\title{
Bandpass filter based on complementary split ring resonators at $\mathrm{X}$-Band
}

\author{
Furqan Furqan, Said Attamimi, Andi Adriansyah, Mudrik Alaydrus \\ Department of Electrical Engineering, Universitas Mercu Buana \\ Jl. Meruya Selatan No 1 Jakarta Barat, 5840816, Indonesia
}

\begin{tabular}{l} 
Article Info \\
\hline Article history: \\
Received Sep 12, 2018 \\
Revised Nov 13, 2018 \\
Accepted Nov 27, 2018 \\
\hline Keywords: \\
Bandpass filter \\
CSRR \\
Substrate integrated waveguide \\
X-band
\end{tabular}

X-band

\begin{abstract}
Complementary Split Ring Resonators were used embedded in a substrate integrated waveguide to generate passband charateristics in X-Band. Based on a parameter study with an electromagnetic commercial software, the characteristics of double and quadruple CSRRs according the reflection and transmission factor were observed. The computer simulation showed, the bandpass filter worked in the frequency range 8.12-8.63 GHz and 8.11$8.63 \mathrm{GHz}$ for double and quadruple CSRR, respectively. The insertion loss was $0.12 \mathrm{~dB}$ and $0.015 \mathrm{~dB}$. The measurement mit a vector network analyzer verified the simulation results. The frequeny range measured was 8.12-8.67 $\mathrm{GHz}$ and $8.12-8.61 \mathrm{GHz}$ for double and quadruple CSRRs, respectively. The measured insertion loss was $0.25 \mathrm{~dB}$ and $0.2 \mathrm{~dB}$.
\end{abstract}

Copyright $@ 2019$ Institute of Advanced Engineering and Science. All rights reserved.

\section{Corresponding Author:}

Mudrik Alaydrus,

Department of Electrical Engineering,

Universitas Mercu Buana,

Jl. Meruya Selatan No 1 Jakarta Barat, 5840816, Indonesia.

Email: mudrikalaydrus@mercubuana.ac.id

\section{INTRODUCTION}

The need for an effective separation of signals with different frequencies reflects in many researches of highly selective bandpass and lowpass filters [1-5]. In [1], a bandpass filter with four open loop rectangular resonators was implemented in lossy substrate. The resonators are not only coupled directly, but also coupled through cross ways, which leads to cancelation of the signal at certain frequencies. This condition produced the transmission zeros of the filter. An improved version of selective bandpass filter was designed in [2]. Here, the approached with direct and cross coupled open loop rectangular resonators still used, however, the filter was implemented in rather small lossy substrate and the number of resonators was increased to six. In this way, four transmission zeros are generated, and due to the small loss of the substrate, the transmission zeros are very clear to see, which generate an attenuation of around $50 \mathrm{~dB}$ near the pass region. In [3] two dual-mode rectangular ring resonators were designed at radio frequency above $20 \mathrm{GHz}$ in multilayer technology. With the cross-coupling between resonators two transmission zeros were generated at lower and upper region of the pass band. An approach to enhance the selectivity of an existing filter was carried out by adding several complementary split ring resonators on the bottom side [4]. The result showed that the bandwidth increased and a pair of transmission zeros were generated due to suitable dimension of the resonators. In [5], compact sized lowpass filters with good performance in selectivity were introduced. The work was based on modification of the ground of a simple microstrip line. The modification of the ground plane, the defected ground structure (DGS), was performed by introducing a Hilbert curve ring and Sierpinski carpet. The simulation and measurement showed sharper selectivity around the cut-off frequency of the filters. 
Some other publications concerned with multiband filter characteristics [6, 7]. Both works made use the concept of stepped impedance to get dualband and heptaband filter behaviours, respectively. Moreover, the designed filters are compact due to folding of the stub structures. In [8], a compact and wideband bandstop filter was studied. This small filter with dimension of 17 x $20 \mathrm{~mm}^{2}$, was made by simply stubbing a rectangular split ring resonator in the mid of the transmission line, which lead to a stopband characteristic at around $2.2 \mathrm{GHz}$. A filter based on a substrate integrated waveguide (SIW) with DGS was studied [9]. The filter worked at frequency between $3.7-4.2 \mathrm{GHz}$ with a return loss better than $17 \mathrm{~dB}$ and an insertion loss of around $1.02 \mathrm{~dB}$. In [10] a microstrip cavity filter for X-band was designed. The filter was integrated in a power divider and coupler.

In this work, some complementary split ring resonators (CSRR) are loaded in a substrated integrated waveguide (SIW) to obtain a bandpass characteristics between $8.12-8.61 \mathrm{GHz}$. In this passband, the reflection factor should be lower than $-15 \mathrm{~dB}$ and the insertion loss should be smaller than $0.3 \mathrm{~dB}$. A parameter study with Sonnet v16.52 is performed to observe the behaviour of double and quadruple CSRR according the reflection and transmission factor.

\section{RESEARCH METHOD}

\subsection{Substrate Integrated Waveguide}

The structure of a substrate integrated waveguide (SIW) is depicted in Figure 1(a). The basic material of an SIW is a substrate with a thickness of $h$ and a relativ permittivity of $\varepsilon_{\mathrm{r}}$. The back and upper side of the SIW is a metallic layer. Specific for an SIW are the two lines of metallic posts with a distance $a$ from each other. Two posts in a line are separated by $p$ (pitch distance) and the diameter of the metallic posts is $d$.
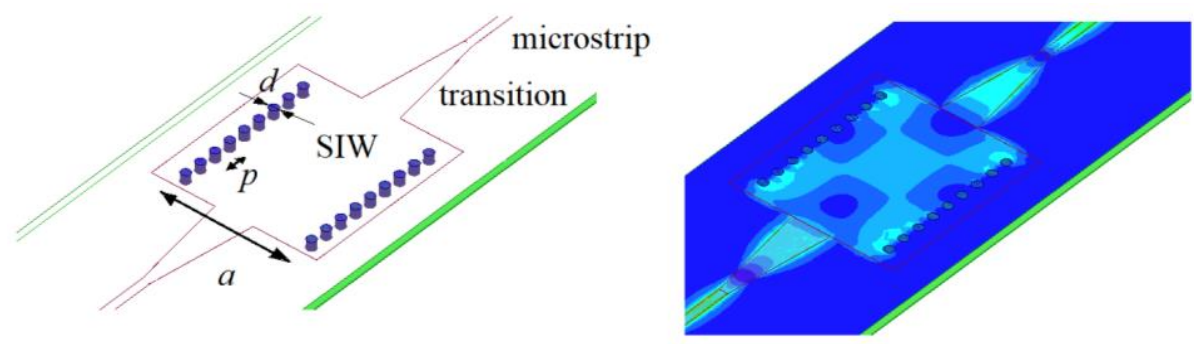

Figure 1. (a) Geometry of subtrate integrated waveguide, (b) Magnetic field distribution above the cut-off frequency

This structure acts like a waveguide, which is able to guide electromagnetic wave having frequencies higher than the cut-off frequency of the SIW. The cut-off frequency of the SIW can be calculated by [11].

$$
f_{c} \approx \frac{c}{2 \sqrt{\varepsilon_{r}}}\left(a-\frac{d^{2}}{0.95 p}\right)^{-1}
$$

Figure 1(b) shows the magnetic field distribution along the SIW for signal frequencies above the cut-off frequency. As long as the pitch distance $p$ small enough, the field distribution is limited inside the SIW with negligibly small energy leakage.

In this work, we used the separation between the post lines $a=13 \mathrm{~mm}$, the diameter of the posts $d=0.8 \mathrm{~mm}$ and the pitch distance $p=1.6 \mathrm{~mm}$. Implementing the SIW in a substrate with relative permittivity of 2.22, these values lead according to eq. (1) to a cut-off frequency of $8.04 \mathrm{GHz}$. In order to connect the SIW to a feeding microstrip line, tapering transitions between those transmission lines are designed [12].

\subsection{Complementary Split Ring Resonator}

A single CSRR embedded on the top of a SIW is depicted in Figure 2(a). This resonator interacts with the fundamental mode of wave propagationg in the SIW (the $\mathrm{H}_{10}$ mode). The coupling between the CSRR and the SIW is described in Figure 2(b) by the parallel resonator circuit containing Lc and Cc and also $\mathrm{R}$ for including possible loss [13]. With this model, there is a possible transmission zero at the frequency 


$$
f_{T Z}=\frac{1}{2 \pi \sqrt{L_{C}\left(C_{C}+C\right)}}
$$

Here, we use RT/Duroid 5880 substrate (dielectric constant $\varepsilon \mathrm{r}=2.22$, thickness $\mathrm{h}=1.58 \mathrm{~mm}$ and tan $\delta=0.002$ ), and in order to get a transmission zero at $9.2 \mathrm{GHz}$, we use $\mathrm{s}=0.3 \mathrm{~mm}, \mathrm{~g}=0.4 \mathrm{~mm}, \mathrm{c}=4 \mathrm{~mm}, \mathrm{~b}=2.2$ $\mathrm{mm}$, and for inner loop, $\mathrm{b}^{\prime}=1 \mathrm{~mm}, \mathrm{c}^{\prime}=2.8 \mathrm{~mm}$.

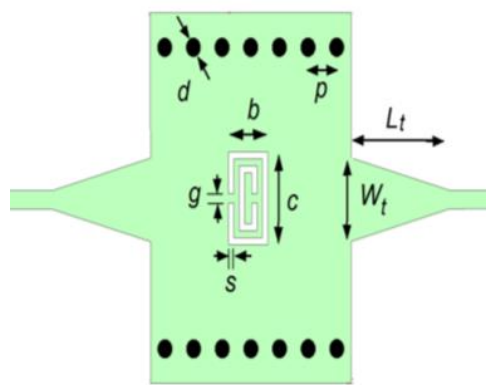

(a)

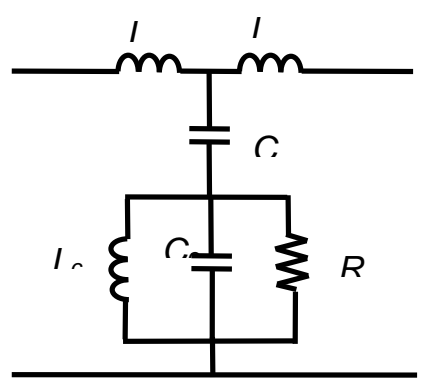

(b)

Figure 2. (a) Single CSRR on the top of the SIW, (b) equivalent circuit describing interaction CSRR and SIW for fundamental mode $\mathrm{H}_{10}$

Smaller values of $\mathrm{b}$ and $\mathrm{c}$, would push the transmission zero to higher frequency. However the dimension of the inner loop becomes smaller and complicated to be manufactured.

\section{RESULTS AND DISCUSSION}

\subsection{Simulation}

In this research, based on the geometry of the CSRR given in Section 2.2, a parameter study is performed. Figure 3(a) gives the bandpass filter with double CSRRs, whereas Figure 3(b) shows the bandpass filter with quadruple CSRRs.

The SIW loaded by a pair of CSRRs has the advantage of increasing return loss, minimizing insertion loss. By adjusting the distance between CSRRs, it will affect the coupling value of CSRRs so that it will affect the performance of the filter such as the resulting middle frequency value, insertion loss, return loss and bandwidth.

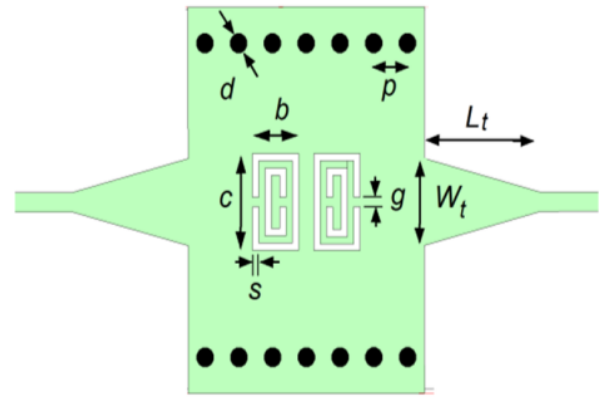

(a)

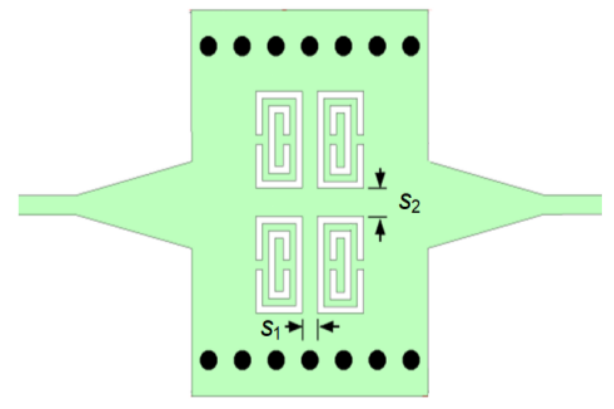

(b)

Figure 3. (a) Structure with double CSRR with $d=0.8 \mathrm{~mm}, p=1.6 \mathrm{~mm}, s=0.3 \mathrm{~mm}, g=0.4 \mathrm{~mm}, c=4$ $\mathrm{mm}, b=2.2 \mathrm{~mm}$, and for inner loop, $b^{\prime}=1 \mathrm{~mm}, c^{\prime}=2.8 \mathrm{~mm}, W_{t}=3.6 \mathrm{~mm}, L_{t}=6.5 \mathrm{~mm}, S_{1}$ separation between CSRR, (b) Structure with quadruple CSRR, same dimension values as in (a) and with separations $S_{1}$ and $S_{2}$

With simulation software Sonnet v.16.52, we simulate the distance variation between CSRRs so the most maximal value can be obtained without changing parameters of CSRRs itself. This variation uses the sweep parameter in the Sonnet setting so that distance can be change from $0.5 \mathrm{~mm}$ to $0.8 \mathrm{~mm}$ by $0.1 \mathrm{~mm}$ step. 
Figure 4(a) shows the reflection $S_{11}$ and transmission factor $S_{21}$ for double CSRRs as function of the separation $S_{1}$. Table 1 gives the important values obtained by this variation. We see in Table 1 , the variation of distance $S_{1}$ has no effect to the midfrequency of the filter, however it has significant impact to the insertion loss and return loss. Through this parameter study, the distance $S_{1}=0.7 \mathrm{~mm}$ gives the optimal result fulfilled the specification given at the beginning. The bandwidth obtained with this distance is around $500 \mathrm{MHz}$ (with respect to return loss bigger than $15 \mathrm{~dB}$ ).

Table 1. Simulation Result for Double CSRRs

\begin{tabular}{ccccc}
\hline $\begin{array}{c}\mathrm{S}_{1} \\
(\mathrm{~mm})\end{array}$ & $\begin{array}{c}\text { Mid } \\
\text { frequency } \\
(\mathrm{GHz})\end{array}$ & $\begin{array}{c}\text { Insertion } \\
\text { loss }(\mathrm{dB})\end{array}$ & $\begin{array}{c}\text { Return } \\
\text { loss }(\mathrm{dB})\end{array}$ & $\begin{array}{c}\text { Bandwidth } \\
(\mathrm{MHz})\end{array}$ \\
\hline 0.5 & 8.50 & 0.47 & 18.65 & 950 \\
0.6 & 8.50 & 0.48 & 14.07 & 700 \\
0.7 & 8.45 & 0.12 & 34.51 & 510 \\
0.8 & 8.50 & 0.17 & 13.34 & 650 \\
\hline
\end{tabular}

Table 2. Simulation Result for Quadruple CSRRs

\begin{tabular}{ccccc}
\hline $\begin{array}{c}\mathrm{S}_{1}, \mathrm{~S}_{2} \\
(\mathrm{~mm})\end{array}$ & $\begin{array}{c}\text { Mid } \\
\text { frequency } \\
(\mathrm{GHz})\end{array}$ & $\begin{array}{c}\text { Insertion } \\
\text { loss }(\mathrm{dB})\end{array}$ & $\begin{array}{c}\text { Return } \\
\text { loss }(\mathrm{dB})\end{array}$ & $\begin{array}{c}\text { Bandwidth } \\
(\mathrm{MHz})\end{array}$ \\
\hline 0.5 & 8.15 & 0.015 & 17.03 & 312 \\
0.6 & 8.25 & 0.090 & 19.84 & 324 \\
0.7 & 8.32 & 0.015 & 42.75 & 515 \\
0.8 & 8.30 & 0.182 & 22.53 & 389 \\
\hline
\end{tabular}

Figure 4(b) gives the reflection $S_{11}$ and transmission factor $S_{21}$ for quadruple CSRRs as function of the separation $S_{1}$ and $S_{2}$. Here, in order to restrict too many cases, we change both distances equal $S_{1}=S_{2}$, and vary them from $0.5 \mathrm{~mm}$ to $0.8 \mathrm{~mm}$. Table 2 highlights the important values obtained by this variation. Here, again the distance $S_{1}=S_{2}=0.7 \mathrm{~mm}$ gives the best values of return loss $42.75 \mathrm{~dB}$ and the smallest insertion loss $0.015 \mathrm{~dB}$. However the mid frequency is little bit shifted to $8.32 \mathrm{GHz}$ with rather unchanged bandwidth of about $515 \mathrm{GHz}$.

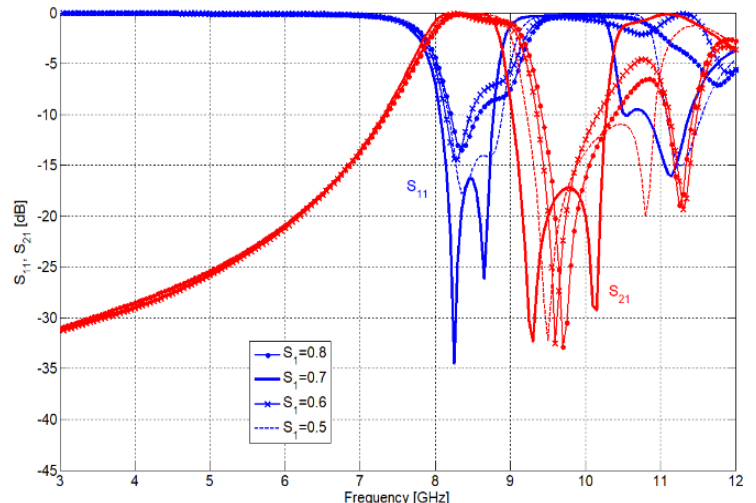

(a)

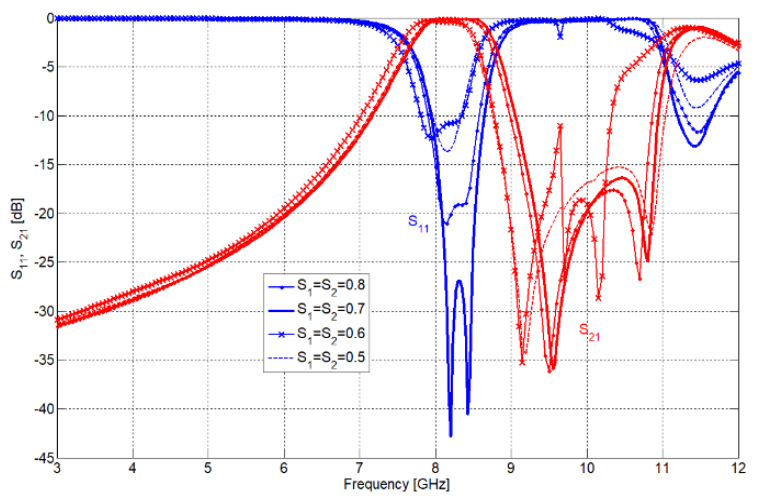

(b)

Figure 4. (a) The reflection $S_{11}$ and transmission factor $S_{21}$ for double CSRRs as function of separation $S_{1}$ (in $\mathrm{mm}$ ), (b) The reflection $S_{11}$ and transmission factor $S_{21}$ for quadruple CSRRs as function of horizontal and vertical separation $S_{1}$ and $S_{2}$ (in $\mathrm{mm}$ )

\subsection{Measurement}

Figure 5 shows the fabricated filters. The SIW filter loaded by quadruple CSRRs has the same dimension like the filter with double CSRRs. The fabricated double CSRR is the model for $S_{1}=0.7 \mathrm{~mm}$, whereas the quadruple CSRRs is the model for $S_{1}=S_{2}=0.7 \mathrm{~mm}$. The overall dimension of the filter is $32 \mathrm{~mm} x$ $16 \mathrm{~mm}$. The filters are connected with SMA connectors and measured by the vector network analyzer ZVA67 from Rohde \& Schwarz.

Figure 6 gives the comparison of simulation and measurement for double and quadruple CSRR. Except of some deviasions in "zero" reflections in the passbands and in "transmission zeros" in stop band due to loss in subtrates, the measured data confirms the simulation results very well. Table 3 gives a comparison between important values obtained by simulation and measurement. The frequency range and the bandwidth are practically unchanged. The insertion loss increases signifantly, however the value is still small. 

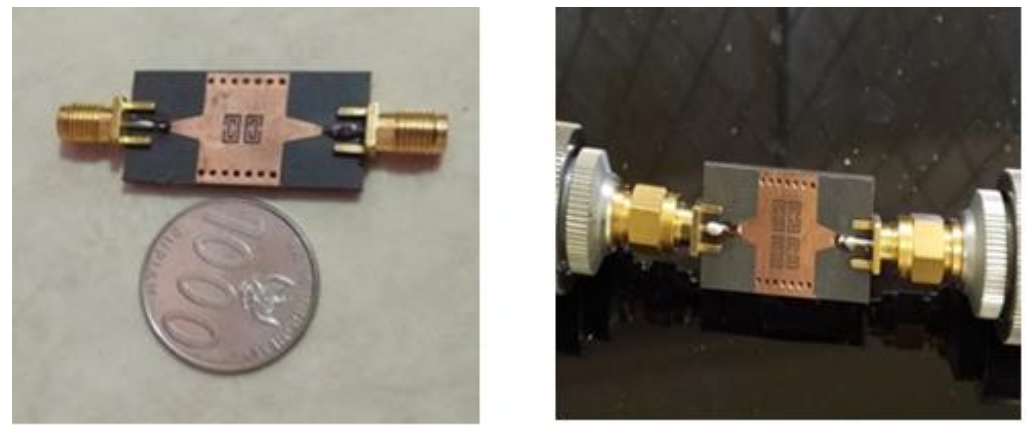

Figure 5. The photograph of fabricated bandpass filters

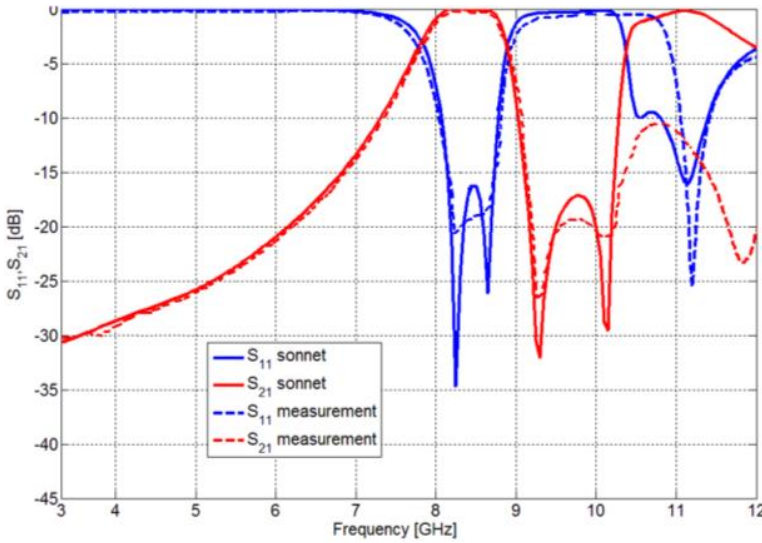

(a)

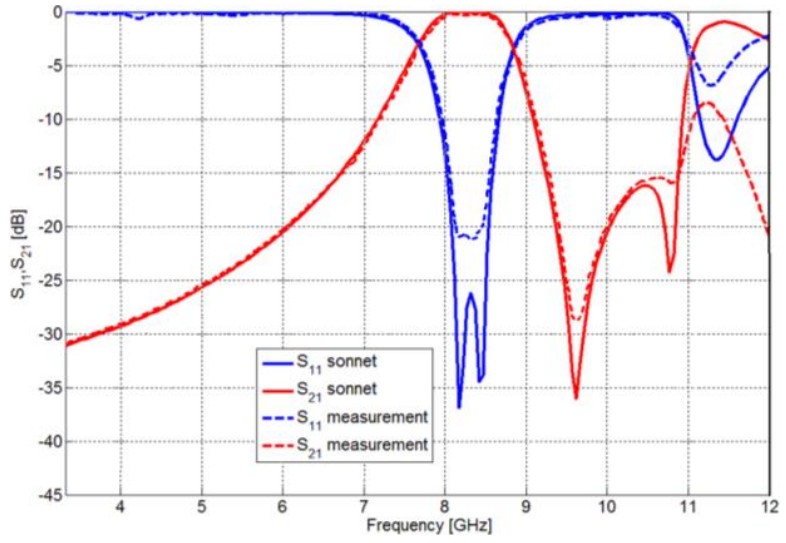

(b)

Figure 6. (a) Comparison of the simulated and measured reflection $\mathrm{S}_{11}$ and transmission factor $\mathrm{S}_{21}$ for double CSRRs for $S_{1}=0.7 \mathrm{~mm}$, (b) Comparison of the simulated and measured reflection $\mathrm{S}_{11}$ and transmission factor $\mathrm{S}_{21}$ for quadruple CSRRs for $\mathrm{S}_{1}=\mathrm{S}_{2}=0.7 \mathrm{~mm}$

Table 3. Comparison Between Simulation Result and Measurements

\begin{tabular}{cccccc}
\hline \multirow{5}{*}{ Simulation } & & $\begin{array}{c}\text { Frequency range } \\
(\mathrm{GHz})\end{array}$ & $\begin{array}{c}\text { Insertion loss } \\
(\mathrm{dB})\end{array}$ & $\begin{array}{c}\text { Return loss } \\
(\mathrm{dB})\end{array}$ & $\begin{array}{c}\text { Bandwidth } \\
(\mathrm{MHz})\end{array}$ \\
\hline \multirow{3}{*}{ Measurement } & Double & $8.12-8.63$ & 0.12 & 34.51 & 510 \\
& Quadruple & $8.11-8.63$ & 0.015 & 42.75 & 515 \\
& Double & $8.12-8.67$ & 0.25 & 18.50 & 550 \\
& Quadruple & $8.12-8.61$ & 0.20 & 21.67 & 490 \\
\hline
\end{tabular}

\section{CONCLUSION}

Two bandpass filters in SIW loaded by several CSRRs were designed. Based on a parameter study, the behaviour of double and quadruple CSRRs according the reflection and transmission factor is observed. The simulation showed, the bandpass filter work in the frequency range $8.12-8.63 \mathrm{GHz}$ and $8.11-8.63 \mathrm{GHz}$ for double and quadruple CSRR, respectively. The insertion loss was $0.12 \mathrm{~dB}$ and $0.015 \mathrm{~dB}$. The measurement confirmed the simulation. The frequeny range measured was $8.12-8.67 \mathrm{GHz}$ and $8.12-8.61$ $\mathrm{GHz}$ for double and quadruple CSRRs, respectively. The measured insertion loss was $0.25 \mathrm{~dB}$ and $0.2 \mathrm{~dB}$. The increasing value in insertion loss was probably due to higher loss in the material.

\section{ACKNOWLEDGEMENTS}

The authors would like to thank KEMENRISTEK DIKTI for the financial support of this research for the period 2017-2018. 


\section{REFERENCES}

[1] Alaydrus M, Widiastuti D, Yulianto T. Designing Cross-coupled Bandpass Filters with Transmission Zeros in Lossy Microstrip. Proceedings of Int. Conf. on Information Technology and Electrical Engineering (ICITEE). Yogyakarta. 2013; 277-280.

[2] Astuti DW, Juwanto J, Alaydrus M. A Bandpass Filter Based on Square Open Loop Resonators at 2.45 GHz. Proceedings of the 3rd Int. Conf. on Instrumentation, Communications, Information Technol., and Biomedical Engineering (ICICI). Bandung. 2013; 147-151.

[3] Wahab Nab, Amiruddin A, Radzuan R., et al. Bandpass Filter Based on Ring Resonator at RF Frequency above 20 GHz. Indonesian Journal of Electrical Engineering and Computer Science. 2018 ; 9 (3); 680-684.

[4] Zhang D, Wu Q, Sha X. High Selective Frequency Response in a Complementary Split Ring Resonator based Transmission Line, Microwave and Optical Technology Letters. 2017; 59 (1):12-15.

[5] Astuti DW, Wahyuni I, Muslim M, Alaydrus M. Lowpass Filter with Hilbert Curve Ring and Sierpinski Carpet DGS, Telkomnika. 2018; 16 (3): 1092-1100.

[6] Firmansyah T, Praptodinoyo S, Wiryadinata R, et al. Dual-wideband Bandpass Filter using Folded Cross-stub Stepped Impedance Resonator. Microwave and Optical Technology Letters. 2017; 59:2929-2934.

[7] Firmansyah T, Praptodiyono S, Pramudyo AS. Chairunnisa C, Alaydrus M. Hepta-band Bandpass Filter Based on Folded Cross-loaded Stepped Impedance Resonator. Electronics Letters. 2017; 53 (16): 1119-1121.

[8] Nasiri B, Errkik A, Zbitou J, Tajmouati, El Abdellaoui L, Latrach M. A New Compact and Wideband Band-Stop Filter Using Rectangular SRR. Telkomnika. 2018; 16 (1): 110-117.

[9] Astuti DW, Jubaidilah A, Alaydrus M. Substrate Integrated Waveguide Bandpass Filter for VSAT Downlink. Proceedings of Int. Conf. on Quality in Research (QiR), Bali. 2017; 101-105.

[10] Maulana YY, Saputera YP, Santiko AB, Setiawan A. Compact Power Divider Integrated with Coupler and Microstrip Cavity Filter for X-Band Surveillance Radar System. Telkomnika. 2017; 15 (1): 227-237.

[11] Huang L, Wu W, Yuan N, Robertson ID. Substrate Integrated Waveguide Filters With Broadside-Coupled Complementary Split Ring Resonators. IET Microwaves, Antennas Propagation. 2013; 7 (10): 795-801.

[12] Alaydrus M. Studi Transisi Saluran Transmisi Planar - Substrate Integrated Waveguide. Incomtech. 2016; 7(2): 237-250.

[13] Zhang XC, Yu ZY, Xu J. Novel Band-pass Substrate Integrated Waveguide (SIW) Filter Based on Complementary Split Ring Resonators (CSRRs). Progress in Electromagnetics Research, PIER 72. 2007: 39-46. 